\title{
Making Video Dance: A Step-by-Step Guide to Creating Dance for the Screen (2nd ed), by Katrina McPherson. 2018. London and New York: Routledge. 280 pp. Black and white images. \$120 hardcover. ISBN 978-1-13-869912-0. \$31.96 paperback. ISBN 978-1-13-869913-7. Website: www.makingvideodance.com.
}

Robin Gee, University of North Carolina, Greensboro

Keywords: video dance, process, editing, production, distribution

As an art-maker, media-lover and would-be researcher I am always on the hunt for works that support the making of art and the people who endeavor to do so. Books that excite and inspire while also providing insight are always high on my list as I scour the aisles of my university library.

The first edition of Making Video Dance by Katrina McPherson is such a text for me - like an old friend, pages worn with highlighted notes, I return to it periodically in the process of both delivering content in university courses and in the making of my own work. The text itself, oft borrowed by both students and colleagues alike, is the quintessential dance film production handbook. I have used it to support the teaching of screendance for several years and have found it to be one of my most treasured guides.

When asked why the first edition was written McPherson stated, "because I could not find one like it... whilst there [were] many texts on film and video making in general, I found none focusing on the specific and unique concerns and possibilities that arise when you make dance for the screen." ${ }^{1}$ Thus, she set out to write a book that aimed to fill a need: to help dancers, choreographers and filmmakers begin the process of collaborating with and in the context of this new medium, finding common ground in both language and approach.

The newest edition of Making Video Dance does just that-it provides the reader with a forthright yet thoughtful look at making dance on film that expands on its predecessor with new insights, contexts and resources that will help artists gain new ground in the areas of pre-production, production, post-production and "flight" - the art of sending one's work out into the world. The chapters have been fleshed out, adapted and contain new material more relevant to a digital age. It is clear that McPherson's years as a filmmaker, curator and choreographer are informing these new sections, from devising and using a score to the history of manifestos in screen dance, she is artfully preparing us for the worlds of presentation and distribution of this medium in the 21 st century. The International Journal of Screendance 10 (2019).

https://doi.org/10.18061/ijsd.v10i0.6851

(c) 2019 Gee. This article is published under a Creative Commons Attribution 4.0 International License (https://creativecommons.org/licenses/by/4.0/) 
Each chapter ends with exercises designed to accompany key stages of the process, "intended to enhance understanding of the topics covered." ${ }^{2}$ The introductions by Ellen Bromberg and Bob Lockyer are beautifully written and provide some overarching historical context to both the need for and need filled by this work.

The book is divided into eleven chapters that take the reader from introductory lessons on how to begin ("Getting Started"), to the importance of having a clear idea when starting a project. That, along with examples of how to develop ideation and creativity if one doesn't have an idea or project in mind constitute the early chapters, asking the questions Where do ideas come from? How are they developed? How are we inspired? McPherson leads the reader through a series of queries that evenly outline the initial stages of the creative process. She challenges us to "make work that interests you," to develop ideas no matter how simple, whether new work or reworked. ${ }^{3}$ As a pedagogue who often interacts with students in the early stages of filmmaking, I inevitably encounter someone who fervently wants to take a live work and translate it to the screen, somehow imaging that the live work will remain the same by simply becoming a film. McPherson reminds us to honor the hybridity of the form, of all the possibility that lies within and to be willing to allow our work to transform.

Chapters 2-3 ("Dance and the Camera" and "Developing the Work") continue with this foundational work, further exploring ways to develop movement material and the basics of how the camera works "in relation to human movement." 4 "Developing the Work" has quite a few new sections and exercises designed to get us to a richer movement experience, including using and devising scores as a way to dig into movement. The role of the camera and how to "see" movement in this new way is also highlighted. These chapters go beyond the first edition with updated illustrations, scores, exercises and commentary. The ways in which we choreograph the camera is extremely important and McPherson deftly traverses this content with ease.

Chapters 4-7 are directed at the process of production and how to take the idea from the page to the set. She illuminates the necessity of "Creating Your On Screen World" and delves into the importance of intentionality and mise-en-scène in clearly articulating the world of a film. Also included in this chapter is more detailed information on the "people who might be involved and what they might do" on a set in "Next Steps."

Chapters 8-10 begin the post-production and editing portion of the book. Here she takes us through the "Preparation and Choreography of The Edit" and the detailed and important work of structuring post, layering in sound, color correction, dubbing and the conspicuous "Future Proofing" of work.

The second edition's chapters largely correspond to the first edition with the most notable additions being expanded exercises, revamped language, and supplementary sections within in the larger chapters. The revision feels broader than its companion and 
the exercises are more closely related to the chapters in which they reside. It is an overall finely tuned updated version of the original text and I am excited to work through the exercises and readings with my students. New to this addition is also the ways in which McPherson allows us entry into her process by including some of her most notable works as examples in specific chapters. When discussing "Themes" in chapter 1 she shares with us her creative processes in the making of Moment where she uses the concept of time and our perception of it as an entry point to thematic choices in filmmaking.

"Out in the World," the last chapter in the revised edition, would likely be my favorite. Here the author goes beyond the perfunctory "handbook" structure to position larger aesthetic questions about art and art making, thoughtfully engaging readers with questions of who we are as artists and how our work may come to define us or be perceived. We are left to imagine a way forward and urged to develop an ongoing practice. She ends this section by connecting the idea of developing this ongoing creative practice, one that is conscious and responsible, with that of creating a manifesto as a way of formalizing one's intentions. She includes examples of several manifestos along with a brief history of those that have existed in screendance.

Overall the sections are robust, and thoroughly cover the material in ways that will keep both novice and professional engaged. The text also has a website included that highlights much of McPherson's work - a treat indeed. Sadly, the films featured on the companion website (https://www.makingvideodance.com) are only trailers and there is a nominal fee to view full versions of the films. Teachers working with the text should keep this in mind when connecting the content to the website examples.

McPherson's experiences as a video dance maker and arts programmer for television give her a unique perspective on the field as a whole, as well as its storied development in Europe in general and the UK in particular. She is of the age of BBC Dance programming, dance broadcast live on television screens in the UK and she brings that knowledge and experience to bear as she prepares this work. She is an also an honest and experienced writer and adroitly leads us through the processes of making dance exclusively with the camera in mind. The work thoroughly and cohesively provides makers and teachers of film avenues further inquiry into this expanding genre. It continues to be the preeminent field-guide for makers of dance on film.

\section{Biography}

Robin Gee, Associate Professor of Dance at UNC Greensboro, holds an MFA in Dance Choreography and Performance from Sarah Lawrence College and specializes in African 
dance techniques, Modern and Caribbean dance forms, and dance designed for the screen. Ms. Gee has performed with several New York based dance companies, including: Ballet Bagata, Maimouna Keita Dance Company and the Cinque Folkloric Dance Company. She is the recipient of the numerous research grants and awards for her work in dance documentation and preservation including: the West African Research Associations' Post Doctoral Fellowship in African Research the Central Piedmont Regional Artists Hub Grant; the AAUW Postdoctoral Research Fellowship, US Fulbright Scholars Award and NC Choreographers Fellowship. She is also Director/Creator of the Greensboro Dance Film Festival.

Email: rmgee@uncg.edu

Website: https://www.greensborodancefilms.org

\section{Notes}

${ }^{1}$ Katrina McPherson, Making Video Dance, 1st edition, 1.

${ }^{2}$ McPherson, Making Video Dance, 2nd edition, 2.

${ }^{3}$ Ibid., 3

${ }^{4}$ Idem.

${ }^{5}$ lbid., 4.

\section{References}

McPherson, Katrina. Making Video Dance: A Step-by-Step Guide to Creating Dance for the Screen. 1st edition. London and New York: Routledge, 2006.

. Making Video Dance: A Step-by-Step Guide to Creating Dance for the Screen. 2nd edition. London and New York: Routledge, 2018.

https://doi.org/10.4324/9781315452654 